\title{
Effects of Moisture Content on Lap-shear, Bending, and Tensile Strength of Lap-jointed and Finger-Jointed Southern Pine using Phenol Resorcinol Formaldehyde and Melamine Urea Formaldehyde
}

Jian Liu, ${ }^{a}$ Kong Yue, ${ }^{\mathrm{a}, *}$ Feng Wang, ${ }^{\mathrm{a}}$ Jinhao Wu, ${ }^{\mathrm{a}}$ Zhongqiu Tang, ${ }^{\mathrm{a}}$ Zhangjing Chen, ${ }^{\mathrm{b}}$ Weidong $\mathrm{Lu},{ }^{\mathrm{a}}$ and Weiqing $\mathrm{Liu}{ }^{\mathrm{a}}$

The bonding performance of the phenol-resorcinol-formaldehyde adhesive (PRF) and melamine-urea-formaldehyde adhesive (MUF) with southern pine as substrates at various moisture contents (MC) was evaluated. The results showed that bonding shear strength with MUF and PRF was negatively related to wood MC, and bonding shear strength with MUF was higher than that of the PRF. The bending and tensile strengths of finger-jointed lumber decreased with wood MC. The bending strength of finger-jointed lumber was affected more by wood than adhesive. However, both wood and adhesive exhibited the same important contribution to the tensile strength.

Keywords: Bonding behavior; Finger-jointed; Moisture content; Glue line

Contact information: a: College of Civil Engineering, Nanjing Tech University, Nanjing 211800, P. R. China; $b$ : Department of Sustainable Biomaterials, Virginia Polytechnic Institute and State University, VA 24060, Blacksburg, VA, USA; *Corresponding author: yuekong@njtech.edu.cn

\section{INTRODUCTION}

Glued Laminated Timber (Glulam) structures have been used worldwide because their dimensions can be much larger than the lumber pieces from which they were made. (Yang et al. 2008; Lestari et al. 2015). Glulam performance is related to the properties of the individual components (Kilic and Celebi 2006; Ren and Frazier 2012). The performance of the adhesive changes as time is increased, which has an important influence on the performance of the glulam. Moreover, climatic conditions, such as moisture content (MC) and temperature, have an important influence on the performance of products (Yue et al. 2017; Liu et al. 2019; Očkajová et al. 2019; Yue et al. 2020). Therefore, it is necessary to investigate the bonding performance of adhesives.

Structural adhesives used in glulam include formaldehyde, epoxy, and isocyanate (Properzi et al. 2001). Formaldehyde is widely used. The formaldehyde pollutes the environment, and urea-formaldehyde glulam has poor performance in water (Ringena et al. 2006; Park et al. 2009). The raw materials of phenolic resin are easy to obtain, and the adhesive has good fire resistance (Stoeckel et al. 2013; Klippel et al. 2014). However, the phenolic resin products have dark brown color that is not preferred in some applications. Also the glueline is hard and brittle. The phenolic resin demands lower MC of the wood ( Na et al. 2005; Brunner et al. 2010), and its cost is much higher than the ureaformaldehyde resin. In addition to the requirement of high bonding strength and high wood failure percentage, structural adhesives must also have the properties of good durability, room temperature curing, low toxicity, reasonable price, long time storage, and convenient use (Stöckel et al. 2010; Clauß et al. 2011; Yue et al. 2019). 
The humidity in air can affect MC of the wood (Mitchell 2018; Hasburgh et al. 2019). The MC is an important factor affecting the strength of the bonded materials because some adhesives are affected by the MC (Bomba et al. 2014; Máchová et al. 2019), and it also has a certain influence on the curing time of the adhesive (Zhou et al. 2017, 2018). Jiang et al. (2017) studied Young's moduli of Chinese fir at four different MC values $(10.3 \%, 12.2 \%, 14.6 \%$, and $16.7 \%)$; the result showed that Young's moduli decreased linearly with increasing MC. The $12 \% \mathrm{MC}$ glulam has a faster cure rate than that of the $22 \% \mathrm{MC}$, and it has higher final strength (Properzi et al. 2016).

The glue line usually is the weakest section of the glulam structures (Bomba et al. 2014). On lap-shear strength of laminated timber, Nadir and Nagarajan (2014) studied the bond strength of polymer vinyl acetate (PVAc) (the hardener was DORUS R 7357) with rubberwood (Hevea spp) and found that the wood-adhesive shear strength was $8.59 \mathrm{MPa}$, which is $64 \%$ of the strength of the solid wood. The wood failure percentage remained at 99.7\%. Sterley et al. (2004) studied European pine shear strength with polyurethane adhesive (PUR) (one-component) in four different pressure conditions (0.5 MPa, $60 \mathrm{~min}$; $1 \mathrm{MPa}, 60 \mathrm{~min} ; 0.5 \mathrm{MPa}, 120 \mathrm{~min} ; 1 \mathrm{MPa}, 120 \mathrm{~min}$ ) at $35 \%$ to $130 \% \mathrm{MC}$. The results showed that the higher pressure $(1 \mathrm{MPa})$ and longer time $(120 \mathrm{~min})$ gave rise to higher shear strength. Moreover, kiln dry (12\% MC) specimens had higher strength than $35 \%$ to 130\% MC specimens. Bomba et al. (2013) studied the dependence of the strength increase in a bonded joint on the curing time. The result showed that the PVAc adhesives (Kleiberit 303, Rhenocoll 3W 4B, and Protovil D4) need 7 days to reach the ultimate strength. On finger joint timber, Hemmasi et al. (2014) studied the elastic properties of oak wood finger joints with polyvinyl acetate (one-component) and isocyanate (the hardener was benzoyl chloride) adhesives. The results showed that polyvinyl acetate had better performance than isocyanate and $10 \mathrm{~mm}$ length joint had better elastic properties than $5 \mathrm{~mm}$ length joints. Piao and Shupe (2016) compared the bending strength of finger joint composite utility poles using resorcinol formaldehyde adhesive. The results showed that the bending strength of composite poles was less than the strength of the solid wood samples but greater than the strength of finger jointed samples. Özçifçi and Yapıcı (2008) studied the influence of adhesives (PVAc, one-component; D-VTKA, one-component), wood species (beech, oak, Scots pine, poplar, and Uludag fir), and finger joint configuration ( $7 \mathrm{~mm}, 14 \mathrm{~mm}$, and $21 \mathrm{~mm}$ long) on the structural performance of the finger-jointed specimens. The wood species was the greatest factor determining the performance of the finger-jointed specimens, followed by the adhesive used, and the type of joint.

The purpose of this study was to investigate the lap-shear, bending, and tensile strength of southern pine lap-jointed and finger-jointed specimens at the different $\mathrm{MC}$ using phenol-resorcinol-formaldehyde adhesive (PRF) and melamine-urea-formaldehyde adhesive (MUF).

\section{EXPERIMENTAL}

\section{Materials}

Commercially available southern pine (Pinus spp.) lumbers of $38 \times 89 \times 3050 \mathrm{~mm}^{3}$ (thickness by width by length) was selected for this study because the species is widely used in modern timber construction. The pieces were free of defects. The specific gravity of southern pine wood was $560 \mathrm{~kg} / \mathrm{m}^{3}$ at $12 \% \mathrm{MC}$.

The selected lumber pieces were randomly divided into three groups (five replicate 
specimens in one group), and they were kept in a condition of $50 \%, 70 \%$, and $90 \%$ relative humidity (RH) at $20{ }^{\circ} \mathrm{C}$ for two weeks or more until they reached the equilibrium MC of $10 \%, 15 \%$, and $20 \%$, respectively (the initial MC was 12\%). The chosen test specimens had specific gravity differences among the specimens less than 5\% to minimize the effect of the specimen on the bonding and mechanical properties.

The adhesives used in this test were PRF (Shenyang Aikehaobo Chemical Co., Ltd. Shenyang, China) and MUF (Henkel Chemical Technology Co., Ltd. Shanghai, China). The properties of the two adhesives are listed in Table 1. The solid contents of PRF and MUF were $35.7 \%$ and $75 \%$, respectively. The adhesive hardeners of PRF and MUF were 100/20 and 100/100, respectively. The hardeners were added into the adhesives and they were homogenized at $200 \mathrm{~L} / \mathrm{min}$ by a mixer running for $3 \mathrm{~min}$.

Table 1. Parameters of PRF and MUF Adhesives

\begin{tabular}{|c|c|c|c|c|c|}
\hline Adhesive & Color & $\begin{array}{c}\text { Main Agent/Hardener } \\
\text { Ratio }(w / w)\end{array}$ & $\begin{array}{c}\text { Solids Content } \\
(\%)\end{array}$ & $\begin{array}{c}\mathrm{pH} \\
\left(25^{\circ} \mathrm{C}\right)\end{array}$ & $\begin{array}{c}\text { Viscosity } \\
(\mathrm{mPa} \cdot \mathrm{s})\end{array}$ \\
\hline PRF & Dark brown & $100 / 20$ & 35.78 & 7.6 & 7500 \\
\hline MUF & Milky & $100 / 100$ & 75.0 & 5.5 & 1500 \\
\hline
\end{tabular}

\section{Lap-shear Strength Test}

The two test specimens of $55 \mathrm{~mm} \times 55 \mathrm{~mm} \times 20 \mathrm{~mm}$ were brushed with PRF and MUF of $250 \mathrm{~g} / \mathrm{m}^{2}$ on one face to form the lap-jointed specimens. The glued area was 50 $\mathrm{mm} \times 50 \mathrm{~mm}$ (Fig. 1). The test specimens were placed on a flat vulcanizer with a pressure of $1 \mathrm{MPa}$ at room temperature $\left(20^{\circ} \mathrm{C}\right)$. The lap-shear strength was tested for $0.5 \mathrm{~h}, 1 \mathrm{~h}, 1.5$ h, 2 h, 3 h, 6 h, 9 h, 12 h, 15 h, 18 h, 21 h, and 24 h at 10\%, 15\%, and 20 MC. Five specimens were used for each condition.

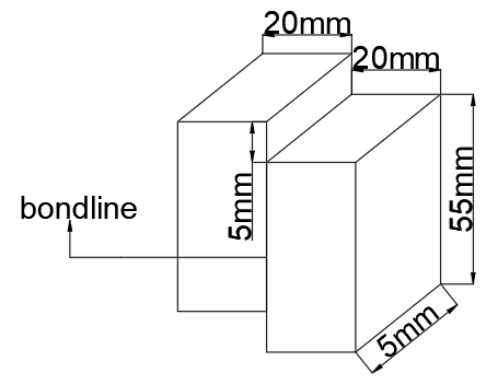

(a)

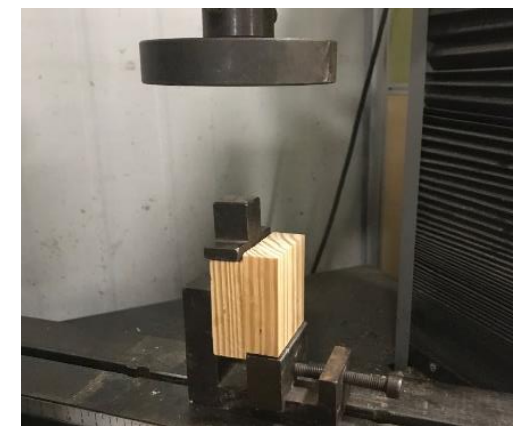

(b)

Fig. 1. The specimen dimensions (a) and test set-up in the lap-shear strength test

The mechanical properties of glued specimens were tested with the microcomputercontrolled universal testing machine (MTS Industrial Systems Co., Ltd. Shanghai, China; $\mathrm{E} 45.305 \mathrm{E})$. The displacement loading rate was $5 \mathrm{~mm} / \mathrm{min}$. The test was conducted at $23 \pm$ $3{ }^{\circ} \mathrm{C}$ and $65 \pm 5 \%$ relative humidity. The shear strength was calculated according to Eq. 1 ,

$$
f_{v}=\frac{Q_{v}}{b \times t_{v}}
$$

where $f_{v}$ is the lap-shear strength of the glue line, in Newtons per square millimeter; $Q_{v}$ is the maximum compressive force applied to the specimens during the test, in Newtons; and $b$ and $t_{v}$ are the width and depth of the bonded overlap section, in millimeters. 
The failure percentage of the lap-shear strength specimens was visually inspected using a magnifying lens. The values were determined at the lowest $10 \%$ increment.

\section{Bending and Tensile tests of Finger Joint Lumber}

The finger-jointed test specimens were $300 \mathrm{~mm} \times 60 \mathrm{~mm} \times 15 \mathrm{~mm}$ (Fig. 2a). The finger-jointed sample was placed at the center of the specimen. The section of tensile specimen was weakened near the finger-jointed area with a cross section of $30 \mathrm{~mm} \times 15$ $\mathrm{mm}$ (Fig. 2b). The finger profile details were plotted in Fig. 2c. A total of 5 replicate specimens were used for each group. The ultimate strength of finger-jointed specimens was tested at an assembly time of $24 \mathrm{~h}$.

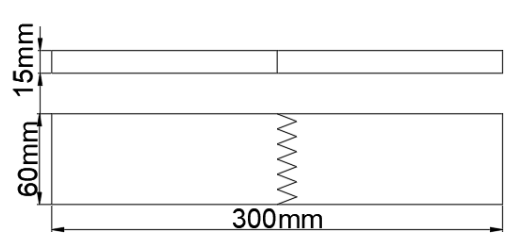

(a)

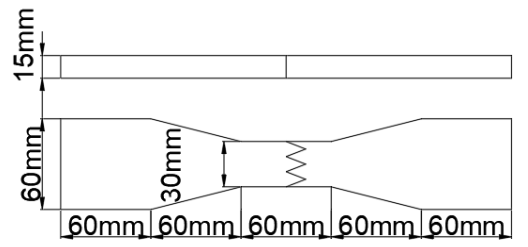

(b)

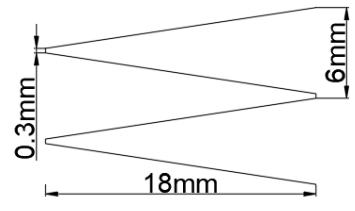

(c)

Fig. 2. Dimension of bending (a) and tensile (b) test specimen and finger profile details (c)

The bending test was conducted on the microcomputer-controlled universal testing machine (MTS Industrial Systems Co., Ltd. Shanghai, China; E45.305E). The four-point load was applied to the bending strength test (Fig. 3a). The tensile test machine was WAW600-G microcomputer-controlled universal testing machine (MTS Industrial Systems Co., Ltd. Shanghai, China; WAW-600-G) (Fig. 3b). The bending tests and tensile tests were conducted with a speed of $5 \mathrm{~mm} / \mathrm{min}$. The bending and tensile strengths were calculated according to Eqs. 2 and 3, respectively,

$$
\begin{aligned}
& f_{m}=\frac{3 \times a \times F_{\max }}{b \times h^{2}} \\
& f_{t 0}=\frac{F_{\max }}{b \times h}
\end{aligned}
$$

where $f_{m}$ is the bending strength, in Newtons $/ \mathrm{mm}^{2} ; f_{t 0}$ is the tensile strength, in Newtons $/ \mathrm{mm}^{2} ; F_{\max }$ is maximum force applied to the specimens during the test, in Newtons; $a$ is the distance between a loading position and the nearest support, $\mathrm{mm}$; and $b$ and $h$ are the width and depth of cross-section, mm.

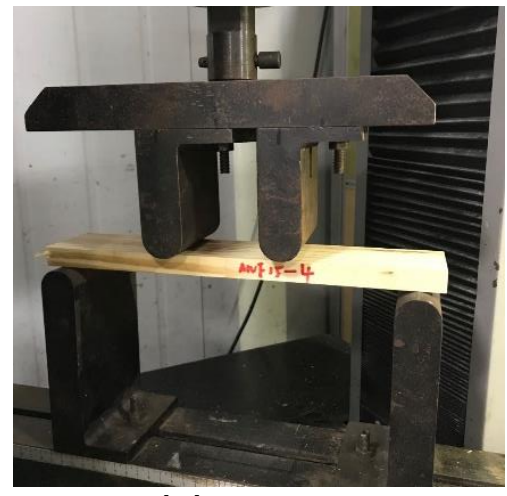

(a)

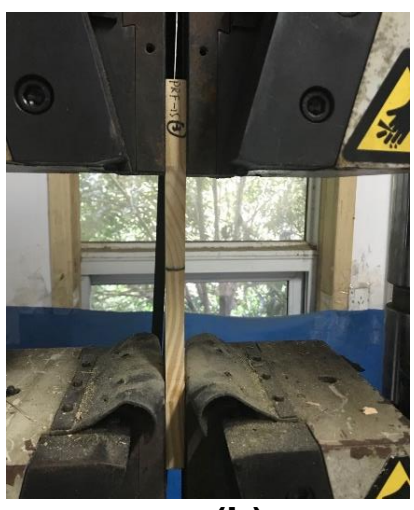

(b)

Fig. 3. Four point bending (a) and tensile (b) test 


\section{RESULTS AND DISCUSSION}

\section{Lap-shear Strength}

In order to determine the curves of lap-shear strength $v s$. time, the strength was tested with $30 \mathrm{~min}$ intervals for the first $6 \mathrm{~h}$, and then $3 \mathrm{~h}$ intervals to $24 \mathrm{~h}$. The shear strengths of PRF and MUF glue line with press time at different MC between $10 \%$ and $20 \%$ are shown in Fig. $4 \mathrm{a}$ and $4 \mathrm{~b}$. The fitting formula (Properizi et al. (2016) was as follows,

$$
\sigma=A_{2}+\frac{A_{1}-A_{2}}{1+e^{\frac{t-t_{0}}{d}}}
$$

where $\sigma$ is the shear strength at the glue line, in Newtons $/ \mathrm{mm}^{2} ; \mathrm{t}$ is the press time, in hour; and $\mathrm{A}_{1}, \mathrm{~A}_{2}, t_{0}$, and $d$ are the fitting parameters (Table 2).

The curing progress can be divided into three stages, including initial rapid growth, slow growth phase, and full solidification phase. During the rapid growth phase, the adhesive undergoes a transition from a liquid to a solid. Its curing strength rapidly increases. When the strength reached a certain value, it began to enter a slow growth phase, when its strength was in small increase, the adhesive began to set. After that, the adhesive solidified. The adhesive was fully cured, and its strength reached the maximum.

Table 2. Parameters of the PRF and MUF Fitting at Different Moisture Content

\begin{tabular}{|c|c|c|c|c|c|c|}
\hline \multirow{2}{*}{ MC (\%) } & Adhesive & \multicolumn{4}{|c|}{ Parameters } & \multirow{2}{*}{ Time (h) } \\
\cline { 3 - 6 } & types & $A_{1}$ & $A_{2}$ & $t_{0}$ & $d$ & \\
\hline \multirow{2}{*}{10} & PRF & -11.37 & 8.25 & -0.74 & 2.69 & 4.8 \\
\cline { 2 - 6 } & MUF & -38.89 & 10.40 & -3.83 & 2.99 & 3.1 \\
\hline \multirow{2}{*}{15} & PRF & -11.16 & 7.76 & -0.95 & 3.09 & 6.1 \\
\cline { 2 - 6 } & MUF & -11.73 & 9.34 & -0.47 & 2.66 & 4.0 \\
\hline \multirow{2}{*}{20} & PRF & -20.39 & 7.10 & -4.47 & 4.43 & 9.6 \\
\cline { 2 - 6 } & MUF & -8.29 & 7.83 & 0.02 & 2.35 & 4.8 \\
\hline
\end{tabular}

As shown in Fig. 4(a), the glue line shear strength of PRF-glulam increased nonlinearly with time. The finger-jointed wood at $10 \% \mathrm{MC}$ had the highest strength increase rate as a function of time, followed by wood at $15 \% \mathrm{MC}$, and then $20 \% \mathrm{MC}$. The ultimate strengths of PRF-glulam at 10\%, 15\%, and 20\% MC were 8.15 MPa, 7.69 MPa, and 7.07 MPa, respectively. The shear strength of wood using PRF adhesive decreased as the $\mathrm{MC}$ increased. The strength decrease was attributed to wood $\mathrm{MC}$ effects on adhesive penetration into wood and it retarded the adhesive curing. Moreover, high MC made the cell wall soften (Miki et al. 2008). As shown in Table 3, the wood failure percentage became higher with increasing time. At $3 \mathrm{~h}$, the wood failure percentage of the PRF-glulam was $20 \%$, indicating that the strength of PRF-glulam mainly depended on the adhesive rather than the wood at this time. At $9 \mathrm{~h}$, the wood failure percentage of $10 \% \mathrm{MC}$ was $90 \%$, and the wood failure percentage of $15 \% \mathrm{MC}$ and $20 \% \mathrm{MC}$ was $80 \%$. Thus, the strength of the PRF-glulam depended mainly on the wood at this time. In order to be used as structural components, the shear strength at the glue line should be higher than $6 \mathrm{MPa}$ (BS EN 386 (2001)). At three MC, The fastest increase in strength occurred at $10 \% \mathrm{MC}$ and it reached the standard strength requirement in $4.8 \mathrm{~h}$. At 15\% MC and 20\% MC, the strengths reached the standard strength requirement in $6.1 \mathrm{~h}$ and $9.6 \mathrm{~h}$ respectively.

In Fig. 4(b), the ultimate lap-shear strength of MUF-glulam at 10\%, 15\%, and $20 \%$ 
MC were $10.37 \mathrm{MPa}, 9.36 \mathrm{MPa}$, and $7.94 \mathrm{MPa}$, respectively. The strengths and wood failure percentages of MUF-glulam were higher than that of PRF-glulam. The MUF had a better bonding performance than PRF. The lap-shear strength of MUF-glulam also decreased as the MC increased. In Table 3, the wood failure percentage of the MUF specimens were similar for each test, indicating the bonding performance of MUF adhesive was hardly influenced by the MC. After $3 \mathrm{~h}$, the wood failure percentage of the MUFglulam was $30 \%$, higher than that of PRF. The MUF had a higher curing speed than PRF because MUF had higher solid content and higher hardener content compared with PRF (Table 1). After $9 \mathrm{~h}$, the wood failure percentage was $100 \%$ at any $\mathrm{MC}$. The strength value of MUF-glulam reached the standard requirements sooner than that of PRF-glulam. The MUF-glulam reached the standard requirement less than $5 \mathrm{~h}$.

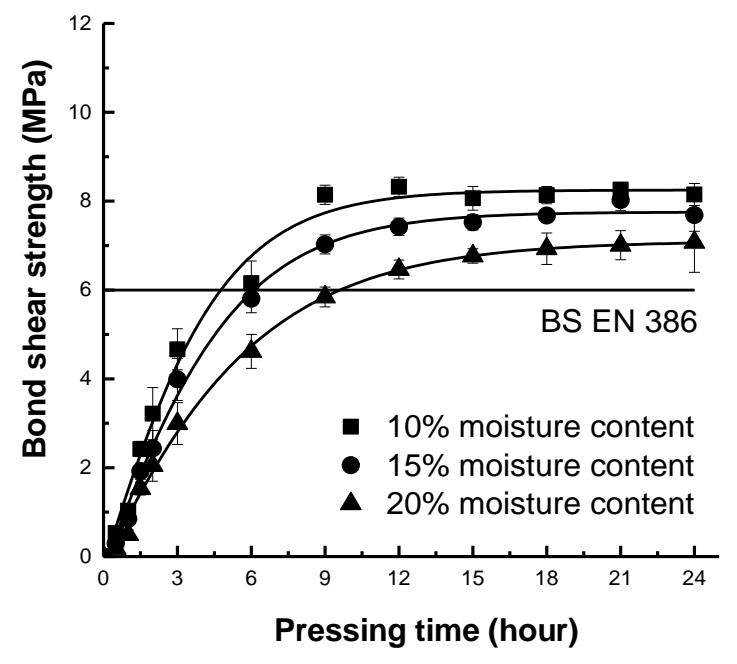

(a)

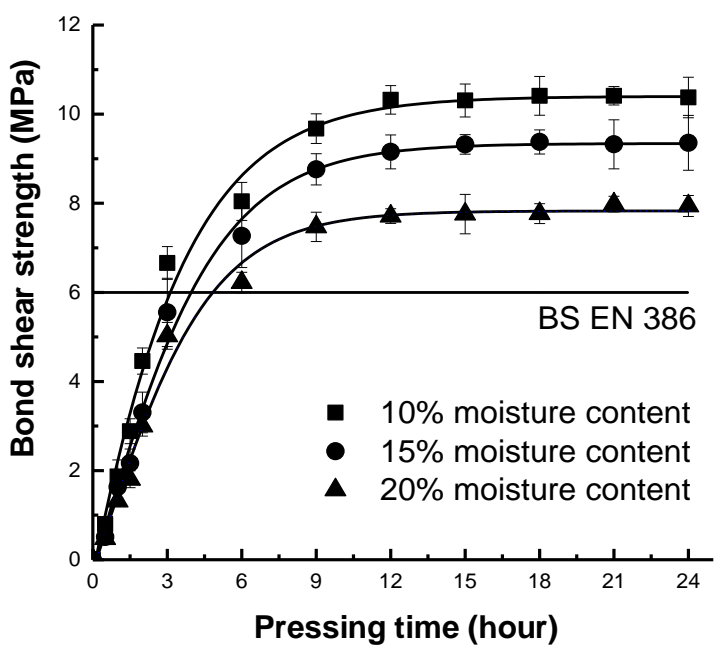

(b)

Fig. 4. Relationship between pressing time and lap-shear strength with PRF (a) and MUF (b).

Table 3. Wood Failure Percentage of the PRF and MUF at Different Pressing Time

\begin{tabular}{|c|c|c|c|c|c|}
\hline \multirow{2}{*}{ Adhesive type } & \multirow{2}{*}{ MC (\%) } & \multicolumn{4}{|c|}{ Wood failure percentage (\%) } \\
\cline { 2 - 6 } & & $3 \mathrm{~h}$ & $6 \mathrm{~h}$ & $9 \mathrm{~h}$ & $18 \mathrm{~h}$ \\
\hline \multirow{3}{*}{ PRF } & 10 & 20 & 50 & 90 & 90 \\
\cline { 2 - 6 } & 15 & 20 & 50 & 80 & 90 \\
\cline { 2 - 6 } & 20 & 20 & 50 & 80 & 90 \\
\hline \multirow{3}{*}{ MUF } & 10 & 40 & 80 & 100 & 100 \\
\cline { 2 - 6 } & 15 & 30 & 80 & 100 & 100 \\
\cline { 2 - 6 } & 20 & 30 & 80 & 100 & 100 \\
\hline
\end{tabular}

\section{Strengths of Finger-Jointed samples}

Figure 5(a) shows the bending strength of MUF and PRF finger jointed samples at $10 \%, 15 \%$, and $20 \% \mathrm{MC}$. The bending strengths of the MUF finger-jointed samples were $70.58 \mathrm{MPa}, 58.6 \mathrm{MPa}$, and $48.28 \mathrm{MPa}$ at $10 \%, 15 \%$, and $20 \% \mathrm{MC}$, and that of PRF-finger joint were $70.45 \mathrm{MPa}, 58.53 \mathrm{MPa}$, and $50.7 \mathrm{MPa}$, respectively. As the $\mathrm{MC}$ increased, the bending strength of the PRF- and MUF-finger joints decreased linearly. The MUF and PRF had the same strength. Different adhesives resulted in similar bending strength while their wood was the same. This result indicated that the bending strengths of PRF- and MUFfinger joints were determined mainly by the wood components, rather than the adhesive. 
Analysis of variation (ANOVA) test with Tukey 95\% confidence intervals was used for the statistical analyses. Table 4 shows the ANOVA results of the bending strength. The P-values for PRF and MUF were 0.007 and 0.000 , which was smaller than 0.05 , indicating that the bending strength had significant difference in different $\mathrm{MC}$.

Figure 5(b) shows the tensile strength of MUF- and PRF-finger joints at 10\%, 15\% and 20\% MC. The tensile strengths of the MUF-finger joint were 53.6 MPa, 52.28 $\mathrm{MPa}$, and $48.31 \mathrm{MPa}$ at $10 \%, 15 \%$, and $20 \% \mathrm{MC}$, respectively. The tensile strength of the PRFfinger joint was $45.83 \mathrm{MPa}, 43.7 \mathrm{MPa}$, and $42 \mathrm{MPa}$, which were $14.5 \%, 16.4 \%$, and $13.1 \%$ lower than that of MUF-finger joint. Different from bending strength, at three different $\mathrm{MC}$, the MUF had higher tensile strength than PRF. As shown in Table 4, the P-values of PRF and MUF were 0.634 and 0.464 , which were higher than 0.05 , indicating that the tensile strength had no significant difference in different $\mathrm{MC}$. This could be attributed to the fact that the parallel to grain tensile strength was insensitive to changed $\mathrm{MC}$, such that the tensile strength changed only 1\% when the MC changed 1\% (Tsoumis 1991). The strength difference between PRF- and MUF- finger-joint specimens could be that the adhesive was different. The tensile strength of finger-jointed specimens was related to the adhesives and the wood substrate. The adhesive affected the tensile strength. Compared with the bending strength, the adhesives in tensile specimens have stronger influence. The importance of adhesive was higher than that of wood substrate when the finger-jointed wood was subjected to tensile loads.

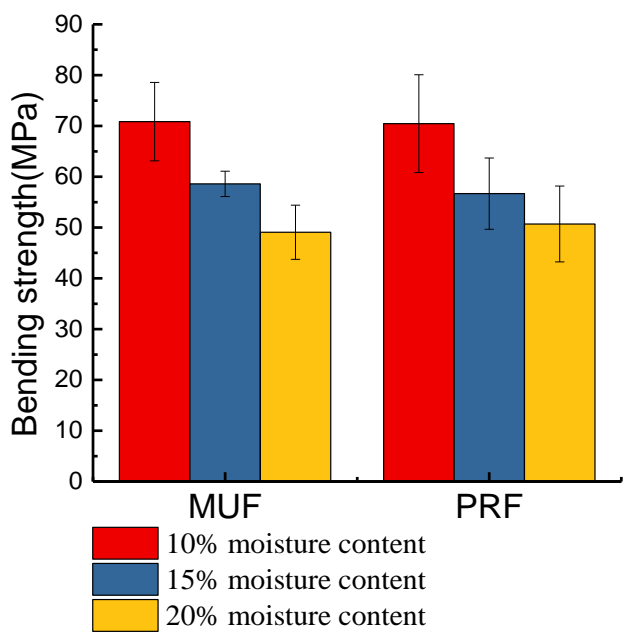

(a)

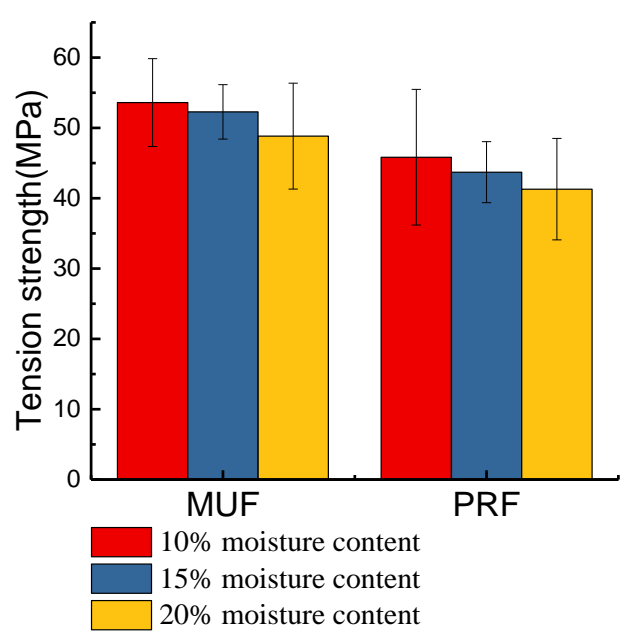

(b)

Fig. 5. Bending (a) and tensile strength (b) of finger-jointed lumber

Table 4. Summary of ANOVA Results of the Bending and Tensile Strengths

\begin{tabular}{|c|c|c|c|c|c|c|c|}
\hline \multirow{2}{*}{ Adhesive } & \multirow{2}{*}{$\begin{array}{c}\text { Treatment } \\
\text { (MC \%) }\end{array}$} & \multicolumn{3}{|c|}{ Bending strength } & \multicolumn{3}{|c|}{ Tensile strength } \\
\hline & & Mean \pm STD & $\mathrm{P}$ value & Remarks & Mean \pm STD & $P$ value & Remarks \\
\hline \multirow{3}{*}{ PRF } & 10 & $70.45 \pm 9.63$ & \multirow{3}{*}{0.007} & \multirow{3}{*}{ VS } & $45.83 \pm 9.64$ & \multirow{3}{*}{0.634} & \multirow{3}{*}{ NS } \\
\hline & 15 & $56.67 \pm 7.00$ & & & $43.70 \pm 4.34$ & & \\
\hline & 20 & $50.70 \pm 7.47$ & & & $41.29 \pm 7.21$ & & \\
\hline \multirow{3}{*}{ MUF } & 10 & $70.85 \pm 7.73$ & \multirow{3}{*}{0.000} & \multirow{3}{*}{ VS } & $53.60 \pm 6.25$ & \multirow{3}{*}{0.464} & \multirow{3}{*}{ NS } \\
\hline & 15 & $58.60 \pm 2.49$ & & & $52.28 \pm 3.86$ & & \\
\hline & 20 & $49.08 \pm 5.33$ & & & $48.84 \pm 7.53$ & & \\
\hline
\end{tabular}

VS: very significant $(P<0.01)$; S: significant $(0.01<P<0.05)$; NS: not significant $(P>0.05)$ 


\section{Fitted Model}

Figure 6 shows the model of the wood lap-shear, bending, and tensile strengths with MC because MC had a great influence on its mechanical performance. The strengths decreased linearly with increasing MC. The lap-shear and tensile strengths of MUF were higher than that of PRF, as MUF had a better bonding performance than PRF. However, the MUF and PRF adhesives had similar strength on finger joint bending strength.

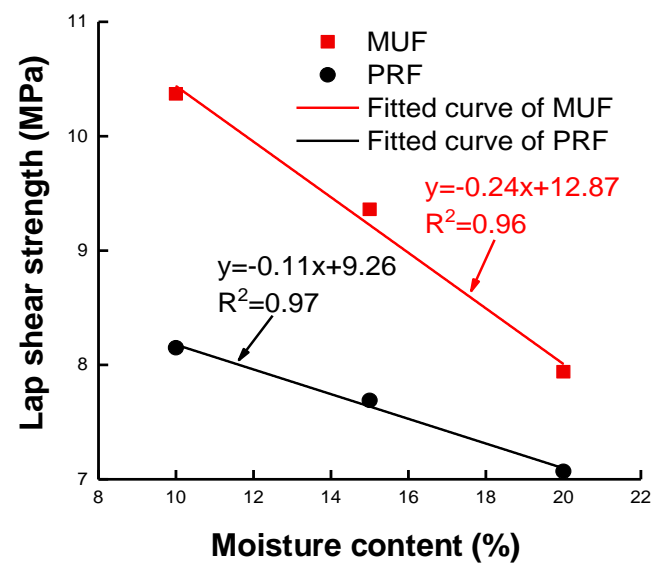

(a)

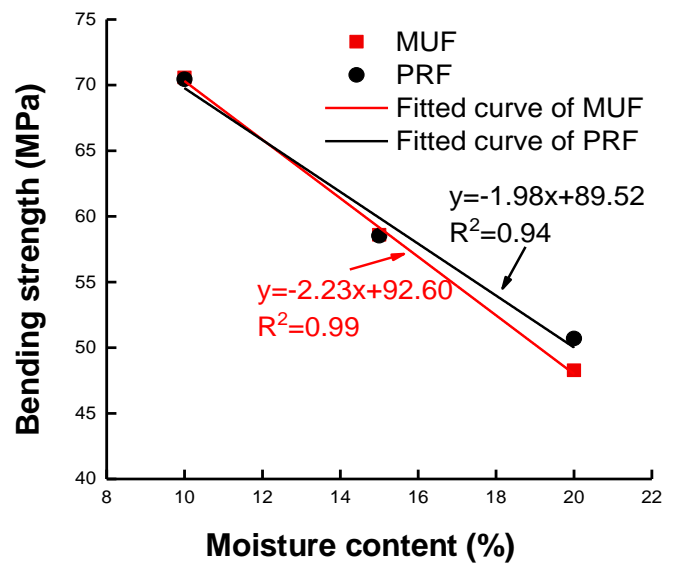

(b)

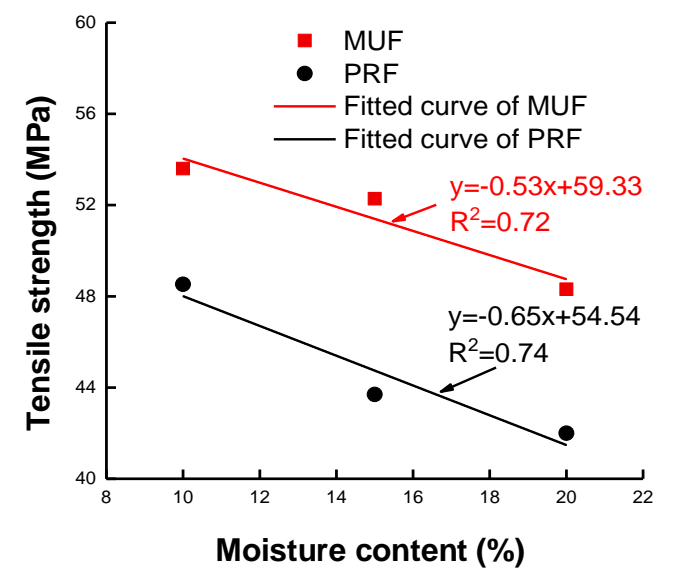

(c)

Fig. 6. Lap-shear (a), bending (b), and tensile (c) strengths as a function of MC

\section{CONCLUSIONS}

1. The strengths of finger-jointed wood specimens using phenol-resorcinol-formaldehyde (PRF) and melamine urea formaldehyde (MUF) adhesives increased with the press time (0 to $24 \mathrm{~h}$ ). The increasing rate for MUF was higher than that of PRF at three different levels of moisture content (MC).

2. The ultimate shear strength decreased linearly with the MC, and the MUF generated a higher ultimate lap-shear strength than the PRF.

3. The bending strength of finger-jointed wood specimens using PRF and MUF was affected more by wood rather than by adhesive. However, for lap-shear and tensile strengths, wood and adhesive equally affected the strengths. 


\section{ACKNOWLEDGEMENTS}

This study was financially supported by National Key Research and Development Program of China (Grant No. 2019YFD1101001), and National Natural Science Foundation of China (Grant No. 51978331).

\section{Declaration of Interest}

No conflict of interest exists in the submission of this manuscript, and the manuscript is approved by all authors for publication. I would like to declare on behalf of my co-authors that the work described was original research that has not been published previously, and not under consideration for publication elsewhere, in whole or in part. All the authors listed have approved the manuscript that is enclosed.

\section{REFERENCES CITED}

Bomba, J., Cvach, J., Šedivka, P., and Kvietková, M. (2013). “Strength increase pattern in joints bonded with PVAc adhesives," BioResources 9(1), 1027-1037. DOI: 10.15376/biores.9.1.1027-1037

Bomba, J., Šedivka, P., Böhm, M., and Devera, M. (2014). "Influence of moisture content on the bond strength and water resistance of bonded wood joints," BioResources 9(3), 5208-5218. DOI: 10.15376/biores.9.3.5208-5218

Brunner, M., Lehmann, M., Kraft, S., Fankhauser, U., Richter, K., and Conzett, J. (2010). "A flexible adhesive layer to strengthen glulam beams," Journal of Adhesion Science and Technology 24(8-10), 1665-1701. DOI: 10.1163/016942410X507759

BS EN 386 (2001). "Glued laminated timber-Performance requirements and minimum production requirements," European Committee for standardization (CEN), Brussels, Belgium.

Clauß, S., Dijkstra, D. J., Gabriel, J., Kläusler, O., Matner, M., Meckel, W., and Niemz, P. (2011). "Influence of the chemical structure of PUR prepolymers on thermal stability," International Journal of Adhesion and Adhesives 31(6), 513-523. DOI: 10.1016/j.ijadhadh.2011.05.005

Hasburgh, L. E., Craft, S. T., Van Zeeland, I., and Zelinka, S. L. (2019). "Relative humidity versus moisture content relationship for several commercial wood species and its potential effect on flame spread," Fire and Materials 43(4), 365-372. DOI: $10.1002 /$ fam. 2707

Hemmasi, A.H., Khademi-Eslam, H., Roohnia, M., Bazyar, B., and Yavari, A. (2014). "Elastic properties of oak wood finger joints with polyvinyl acetate and isocyanate adhesives," BioResources 9(1), 849-860. DOI: 10.15376/biores.9.1.849-860

Jiang, J., Bachtiar, E.V., Lu, J., and Niemz, P. (2017). "Moisture-dependent orthotropic elasticity and strength properties of Chinese fir wood," European Journal of Wood and Wood Products 75(6), 927-938. DOI: 10.1007/s00107-017-1166-y

Kilic, M., and Celebi, G. (2006). "Compression, cleavage, and shear resistance of composite construction materials produced from softwoods and hardwoods," Journal of Applied Polymer Science 102(4), 3673-3678. DOI: 10.1002/app.24153

Klippel, M., Clauß, S., and Frangi, A. (2014). "Experimental analysis on small-scale finger-jointed specimens at elevated temperatures," European Journal of Wood and Wood Products 72(4), 535-545. DOI: 10.1007/s00107-014-0810-z 
Lestari, A.S.R.D., Hadi, Y.S., Hermawan, D., and Santoso, A. (2015). “Glulam properties of fast-growing species using mahogany tannin adhesive," BioResources 10(4), 74197433. DOI: 10.15376/biores.10.4.7419-7433

Liu, J., Yue, K., Xu, L., Wu, J., Chen, Z., Wang, L., Liu, W., and Lu, W. (2019). "Bonding performance of melamine-urea-formaldehyde and phenol-resorcinolformaldehyde adhesive glulams at elevated temperatures," International Journal of Adhesion and Adhesives 102500. DOI: 10.1016/j.ijadhadh.2019.102500

Máchová, E., Langová, N., Réh, R., Joščák, P., Krišták, L'., Holouš, Z., Igaz, R., and Hitka, M. (2019). "Effect of moisture content on the load carrying capacity and stiffness of corner wood-based and plastic joints," BioResources 14(4), 8640-8655. DOI: 10.15376/biores.14.4.8640-8655

Miki, T., Takeuchi, K., Sugimoto, H., and Kanayama, K. (2008). "Material development from wood powder without adhesive by vapor steaming compaction process," Journal of Materials Processing Technology 199(1-3), 396-401. DOI: 10.1016/j.jmatprotec.2007.08.010

Mitchell, P. H. (2018). "Calculating the equilibrium moisture content for wood based on humidity measurements," BioResources 13(1), 171-175. DOI:

10.15376/biores.13.1171-175

Na, B., Lu, X., and Pizzi, A. (2005). "Green wood gluing by traditional honeymoon PRF adhesives," Holz als Roh- und Werkstoff 63(6), 473-474. DOI: $10.1007 / \mathrm{s} 00107-005-0001-\mathrm{Z}$

Nadir, Y., and Nagarajan, P. (2014). "The behavior of horizontally glued laminated beams using rubber wood," Construction and Building Materials 55, 398-405. DOI: 10.1016/j.conbuildmat.2014.01.032

Očkajová, A., Barcík, Š., Kučerka, M., Koleda, P., Korčok, M., and Vyhnáliková, Z. (2019). "Wood dust granular analysis in the sanding process of thermally modified wood versus its density," BioResources 14(4), 8559-8572. DOI: 10.15376/biores. 14.4.8559-8573

Özçifçi, A., and Yapıc1, F. (2008). "Structural performance of the finger-jointed strength of some wood species with different joint configurations," Construction and Building Materials 22(7), 1543-1550. DOI: 10.1016/j.conbuildmat.2007.03.020

Park, B.-D., Lee, S.-M., and Roh, J.-K. (2009). "Effects of formaldehyde/urea mole ratio and melamine content on the hydrolytic stability of cured urea-melamineformaldehyde resin," European Journal of Wood and Wood Products 67(1), 121. DOI: $10.1007 / \mathrm{s} 00107-008-0277-\mathrm{x}$

Piao, C., and Shupe, T. (2016). "Mechanical properties of finger-jointed wood from composite utility poles made of small diameter timber," Drvna industrija 67(1), 7378. DOI: $10.5552 /$ drind.2016.1436

Properzi, M., Pizzi, A., and Uzielli, L. (2016). "Comparative wet wood glueing performance of different types of glulam wood adhesives," Holz als Roh- und Werkstoff 61(1), 77-78. DOI: 10.1007/s00107-002-0347-4

Properzi, M., Pizzi, A., and Uzielli, L. (2001). "Honeymoon MUF adhesives for exterior grade glulam," Holz als Roh-und werkstoff 59(6), 413-421. DOI: $10.1007 / \mathrm{s} 001070100245$

Ren, D., and Frazier, C.E. (2012). "Wood/adhesive interactions and the phase morphology of moisture-cure polyurethane wood adhesives," International Journal of Adhesion and Adhesives 34, 55-61. DOI: 10.1016/j.ijadhadh.2011.12.009

Ringena, O., Janzon, R., Pfizenmayer, G., Schulte, M., and Lehnen, R. (2006). 
"Estimating the hydrolytic durability of cured wood adhesives by measuring formaldehyde liberation and structural stability," Holz als Roh-und Werkstoff 64(4), 321-326. DOI: 10.1007/s00107-005-0087-3

Stöckel, F., Konnerth, J., Kantner, W., Moser, J., and Gindl, W. 2010. "Mechanical characterisation of adhesives in particle boards by means of nanoindentation," European Journal of Wood and Wood Products 68(4), 421-426. DOI: 10.1007/s00107-009-0380-7

Sterley, M., Blümer, H., and Wålinder, M.E.P. (2004). "Edge and face gluing of green timber using a one-component polyurethane adhesive," Holz als Roh-und Werkstoff 62(6), 479-482. DOI: 10.1007/s00107-004-0517-7

Stoeckel, F., Konnerth, J., and Gindl-Altmutter, W. (2013). "Mechanical properties of adhesives for bonding wood-A review," International Journal of Adhesion and Adhesives 45, 32-41. DOI: 10.1016/j.ijadhadh.2013.03.013

Tsoumis, G. (1991). Science and Technology of Wood: Structure, Properties, Utilization, Van Nostrand Reinhold, New York.

Yang, T.-H., Wang, S.-Y., Lin, C.-J., and Tsai, M.-J. (2008). "Evaluation of the mechanical properties of Douglas-fir and Japanese cedar lumber and its structural glulam by nondestructive techniques," Construction and Building Materials, 22(4), 487-493. DOI: 10.1016/j.conbuildmat.2006.11.012

Yue, K., Chen, Z., Lu, W., Liu, W., Li, M., Shao, Y., Tang, L., and Wan, L. (2017). "Evaluating the mechanical and fire-resistance of modified fast-growing Chinese fir timber with boric-phenol-formaldehyde resin," Construction and Building Materials 154, 956-962. DOI:10.1016/j.conbuildmat.2017.08.035

Yue, K., Wang, L., Xia, J., Zhang, Y., Chen, Z., and Liu, W. (2019). 'Experimental research on mechanical properties of laminated poplar wood veneer/plastic sheet composites," Wood and Fiber Science 51(3), 320-331. DOI:10.22382/wfs-2019-030

Yue, K., Wu, J., Xu, L., Tang, Z., Chen, Z., Liu, W., and Wang, L. (2020). 'Use impregnation and densification to improve mechanical properties and combustion performance of Chinese fir," Construction and Building Materials 118101. DOI:10.1016/j.conbuildmat.2020.118101

Zhou, J., Yue, K., Lu, W., Chen, Z., Cheng, X., Liu, W., Jia, C., and Tang, L. (2017). "Bonding performance of melamine-urea-formaldehyde and phenol-resorcinolformaldehyde adhesives in interior grade glulam," Journal of Adhesion Science and Technology 31(23), 2630-2639. DOI: 10.1080/01694243.2017.1313185

Zhou, J., Yue, K., Lu, W., Cheng, X., Liu, W., Jia, C., and Tang, L. (2018). "Effect of CMC formic acid solution on bonding performance of MUF for interior grade glulam," Cellulose Chemistry and Technology 52(3-4), 239-245.

Article submitted: January 21, 2020; Peer review completed: March 21, 2020; Revised version received and accepted: March 26, 2020; Published: March 30, 2020.

DOI: 10.15376/biores. 15.2.3534-3544 